\title{
Prevalence of Caesarean Sections in Mosul City Hospitals :A Cross - Sectional Study
}

\begin{abstract}
Noor Nazar Fadhl* , Omaima Abdulrazzaq Zubair**, Raida Muhammed Al-Wazzan*** *Postgraduate Student, Department of Family and Community Medicine , College of Medicine University of Mosul , **Department of Family and Community Medicine , College of Medicine , University of Mosul , ${ }_{\star \star *}$ Department of Obstetrics and Gynecology , College of Medicine , University of Mosul , Mosul, Iraq Correspondence: noor.nazar.fadel@gmail.com
\end{abstract}

(Ann Coll Med Mosul 2020; 42 (2):126-132).

Received: $7^{\text {th }}$ Nove. 2020; Accepted: $24^{\text {th }}$ Nove. 2020.

\section{ABSTRACT}

Background: Caesarean section rates had been increasing markedly in the world and the procedure as it become more safe than before (although it still a major surgical operation) and the objective of this study is to estimate the prevalence of caesarean section in Mosul city hospitals.

Methods: A cross-sectional study was conducted at eight hospitals in Mosul city from both river sides including five governmental hospitals and three private hospitals, (671) women who delivered by caesarean section in Mosul city hospitals during a period of data collection were included from beginning 15th of November 2019 and ending at 15th of April 2020.

Results: Women delivered by caesarean section aged between $20-35$ years in $(70.6 \%),(74.8 \%)$ of low educational level and (91.8\%) were unemployed. The rate of caesarean section during the period of data collection in Mosul city hospitals was (28.8\%) while the rate of caesarean section during the period of data collection showed that the highest rate of caesarean section were in private hospital and especially at AlZahrawi and Al-Rabee Private Hospitals (100\%) while Al-Batool Hospital include (37.6\%) from governmental hospitals in spite that the highest numbers of deliveries and caesarean section was in Al-Khansa Teaching Hospital.

Conclusions: Caesarean section rate was higher than WHO recommendation among Mosul hospitals. Further improvement and attention to primary health care should be applied.

Keywords: Caesarean section, COVID-19, deliveries, Mosul city hospitals, prevalence.

$$
\begin{aligned}
& \text { انتشار العمليات القيصرية في مستشفيات مدينة الموصل : دراسة المقطع العرضي }
\end{aligned}
$$

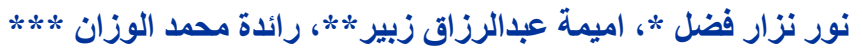

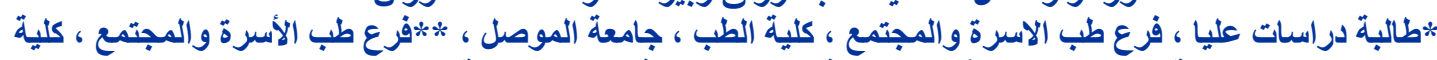

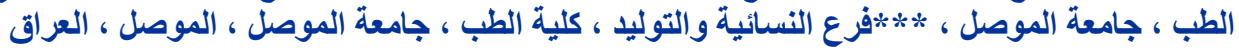

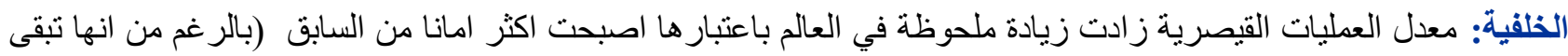

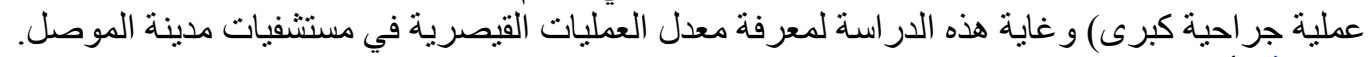

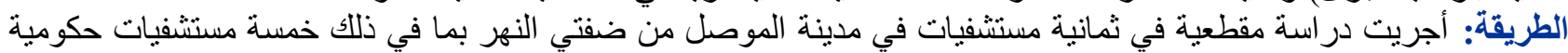

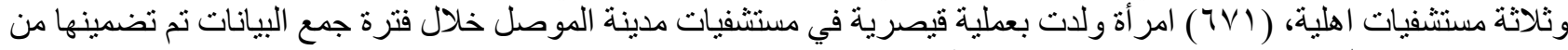

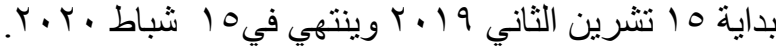

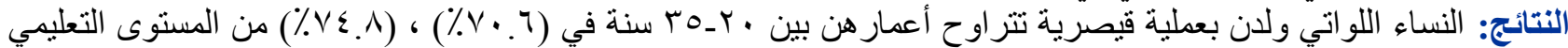

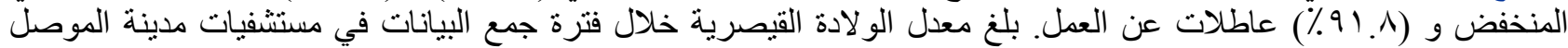

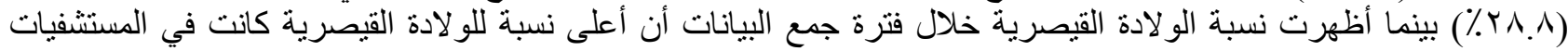

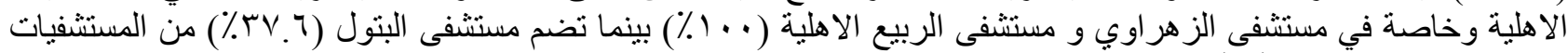

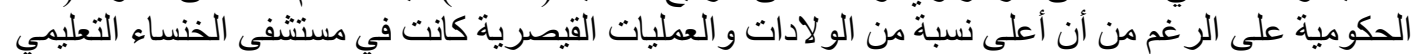

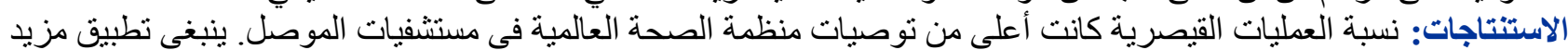
من التحسين و الاهتمام بالر عاية الصحية الأولية. 
الكلمات المفتاحية: الولادة القيصرية، كوفيد-9 (، الولادات، مستشفيات مدينة الموصل، الانتشار .

\section{INTRODUCTION}

Caesarean section (CS) started to be done when the abdomen of dying women were incised and opened to save a fetus and avoid burying it with their mother during 600 before century and at the beginning of the $21^{\text {st }}$ century CS rates was raised above (10-15\%) which was recommended by WHO in many areas of the world especially in high and middle income countries. ${ }^{1}$

Although CS was relatively safe, it is a major surgery and recovery that was relatively longer than that of the vaginal birth, CS was initiated as a lifesaving procedure in clinical practice for both the fetus and the mother. Also, it was considered as one of the most emergency obstetrical operation. ${ }^{2}$

In Iraq the CS rate in 2016 was $(33.1 \%)^{3}$ which was higher than reported in 2012 (24.4\%). ${ }^{4}$ In Nineveh governorate the rate of CS was (15.2\%) in $2012^{4}$ and remained increasing to reach (18.7\%) in 2018 but during 2019 the rate slightly decreased to reach (17.2\%). ${ }^{5,6}$ In Mosul city hospitals the CS rate during 2018 was (22\%) and increased to reach (25.7\%) during 2019 . $^{7,8}$

The CS rates during 2018 in the different governorates of Iraq revealed variations in the rate and ranging from $(14.2 \%)$ in the governorate of $\mathrm{Al}$ Anbar to (52.9\%) in the governorate of Erbil. ${ }^{5}$

The rate of CS in Iraq neighboring countries is variable; in Saudi Arabia the rate of CS reported to be high (43\%) in 2018. ${ }^{9}$ In Jordan, during 2011 2012 CS rate was $(29.1 \%) .{ }^{10}$ In Syria, the rate of CS was still increased to reach (46\%) in $2016 .{ }^{11}$ In Turkey, the CS rate in 2017 was (53.1\%). ${ }^{12}$ In Iran, the CS rate in 2015 still high and it constituted $(43.0 \%){ }^{13}$

In some of developing countries, in Egypt the CS rate during 2016 was $(55.5 \%) .{ }_{15}^{14}$ In Bangladesh, during 2013 , CS rate was (35\%). ${ }^{15}$

In some of developed countries in Canada the rate increased gradually to reach (28.2\%) in $2016 .^{16}$ In Italy, the CS rate was (34.2\%) in $2015 .^{17}$

Caesarean sections are classified according to the urgency as following: Elective CS (scheduled or planned) the decision to do CS may be performed antepartum. It may be done if there is a medical, obstetrical reason or maternal request. The ideal time to do it is a bout (39) weeks of pregnancy unless there is a medical indication ${ }^{18}$ while emergency CS (unscheduled or unplanned) was done when vaginal delivery was planned but reason for CS was happened suddenly, the decision to do it after labor has begun but it may also arise even when labor has not occurred. The morbidity and mortality were observed more with emergency CS than elective. ${ }^{19}$ The aim of this study was estimation of prevalence of CS in Mosul city hospitals.

\section{METHODS}

The current study is a descriptive cross-sectional study which was conducted at Mosul city hospitals during the period of data collection which was five months started from the $15^{\text {th }}$ of November 2019, (671) cases of CS were studied from all hospitals in Mosul city (Al-Khansa, Al-Salam, Al-Batool, Mosul General Hospital, Nablus, Al-Zahrawi, AlRabee and Nineveh hospitals). Data were taken from interview with women who delivered by CS, the women who refused to participate in this study was excluded and the information confirmed by the patient 's medical sheet. The information included the socio demographic characteristics, types of CS and mother preference to delivery types among study population. Questionnaires were filled and the information were entered on Microsoft Excel 2010 then use SPSS version 23 and mini tab for statistical analyses with Chi-square test (goodness of fit) for strata justification, analysis and percent were created for variables also tables and figures were used to the current informations, descriptive statistics was used to show frequencies, percentage, mean and standard deviation of the characters and variables with $P$ - value $(<0.05)$ was considered to be statistical significant.

\section{RESULTS}

Total no. of women with CS included in this study were (671) women, the age of (20-35) years old was $(70.6 \%)$ mean age of the participants women was (28.89 )years $(S D \pm 6.61)$ with a minimum and maximum age of (15 and 47$)$ years with significant statistical difference $(P=0.000)$. Most of women delivered by CS (74.8\%) were illiterate and primary school level and the highest number had primary school (48.4\%) with a significant statistical difference $(P=0.000)$ while the high education was constituted (10.6\%). Most of the participant were unemployed $(91.8 \%)$ with a significant statistical difference $(P=0.000)$ as appeared in table 1: 
Table 1: The socio demographic characteristics of the study population

\begin{tabular}{|c|c|c|c|}
\hline Parameters $(n=671)$ & No. & $\%$ & P-value \\
\hline \multicolumn{4}{|l|}{ Age (years) } \\
\hline$<20$ & 49 & 7.3 & \multirow{3}{*}{0.000} \\
\hline $20-35$ & 474 & 70.6 & \\
\hline$\geq 35$ & 148 & 22.1 & \\
\hline Mean age \pm SD & \multicolumn{2}{|c|}{$28.89 \pm 6.61$} & \\
\hline \multicolumn{4}{|l|}{ Maternal education } \\
\hline Illiterate & 177 & 26.4 & \multirow{5}{*}{0.000} \\
\hline Primary school & 325 & 48.4 & \\
\hline Secondary school & 98 & 14.6 & \\
\hline University & 67 & 10.0 & \\
\hline Higher education & 4 & 0.6 & \\
\hline \multicolumn{4}{|l|}{ Maternal employment } \\
\hline Unemployed & 616 & 91.8 & 0.000 \\
\hline Employed & 38 & 5.7 & \\
\hline Skilled work & 17 & 2.5 & \\
\hline
\end{tabular}

${ }^{*}$ Chi-square test (Goodness of Fit) was used.

The rate of CS in Mosul city hospitals during study period was (28.8\%) and the rate was lower (18.2\%) when calculated for all deliveries (home and hospitals deliveries) in Mosul city. The rate of CS during the period of data collection showed that the highest rate of CS in private hospital were Al-Zahrawi Private Hospital and Al-Rabee Private Hospitals (100\%) while in governmental hospitals the highest rate was AlBatool Hospital (37.6\%) although the highest numbers of deliveries and CS was in Al-Khansa Teaching Hospital, the lowest rate of CS was in Nablus Hospital (15.4\%) as appeared in table 2:

Table 2: Proportion of caesarean section from total deliveries during the study period in Mosul hospitals

\begin{tabular}{|l|c|c|c|c|}
\hline \multicolumn{1}{|c|}{ Name of the hospitals } & No. of CS & $\begin{array}{c}\text { Total } \\
\text { Deliveries }\end{array}$ & $\begin{array}{c}\text { \% of } \\
\text { CS }\end{array}$ & \% of total CS* \\
\hline Al-Zahrawi Private Hospital & 907 & 907 & 100.0 & 13.9 \\
\hline Al-Rabee Private Hospitals & 377 & 377 & 100.0 & 5.8 \\
\hline Nineveh Private Hospital & 237 & 248 & 95.6 & 3.6 \\
\hline Al-Batool Hospital & 1479 & 3929 & 37.6 & 22.7 \\
\hline Mosul General Hospital & 471 & 1980 & 23.8 & 7.2 \\
\hline Al-Khansa Teaching Hospital & 1794 & 7923 & 22.6 & 27.5 \\
\hline Al-Salam Teaching Hospital & 663 & 3399 & 19.5 & 10.2 \\
\hline Nablus Hospital & 594 & 3861 & 15.4 & 9.1 \\
\hline Total deliveries in Mosul hospitals & 6522 & 22624 & 28.8 & 100.0 \\
\hline Total deliveries in Mosul city & 6522 & $35919^{* *}$ & 18.2 & - \\
\hline
\end{tabular}

* The denominator $=6522$

** Which include total deliveries inside and outside hospitals $(22624,13295)$ respectively.

The total prevalence of CS in the current study was (28.8\%). Most of deliveries (76.7\%) were in governmental hospitals while (23.3\%) in private hospitals as appeared in table 3: 
Table 3 : Distribution of types of deliveries in Mosul city hospitals according to the types of hospitals

\begin{tabular}{|c|c|c|c|c|c|c|c|}
\hline \multirow{2}{*}{ Types of hospitals } & \multicolumn{3}{|c|}{ CS among all } & \multicolumn{3}{c|}{ VD among all $^{*}$ Total } \\
\cline { 2 - 7 } & No. & $\begin{array}{c}\% \\
\text { (CS) }\end{array}$ & $\begin{array}{c}\% \\
\text { (Deliveries) }\end{array}$ & No. & $\begin{array}{c}\% \\
\text { (VD) }\end{array}$ & $\begin{array}{c}\text { \% } \\
\text { (Deliveries) }\end{array}$ & Deliveries \\
\hline Governmental & 5001 & 76.7 & 22.1 & 16091 & 99.9 & 71.1 & 21092 \\
\hline Private & 1521 & 23.3 & 6.7 & 11 & 0.1 & 0.1 & 1532 \\
\hline Total & 6522 & 100.0 & 28.8 & 16102 & 100.0 & 71.2 & 22624 \\
\hline
\end{tabular}

*VD mean vaginal delivery

CS rate in the left side was more than the right side. It constituted $(57.4 \%)$ from total CS rate although numbers of hospitals from left side was equal to right side as appeared in table 4:

Table 4 : Distribution of types of deliveries by Mosul sides of river Tigris

\begin{tabular}{|c|c|c|c|c|c|c|c|}
\hline \multirow{2}{*}{ Mosul sides } & \multicolumn{3}{|c|}{ CS among all } & \multicolumn{3}{c|}{ VD among all } & \multirow{2}{*}{$\begin{array}{c}\text { Total } \\
\text { Deliveries }\end{array}$} \\
\cline { 2 - 7 } & No. & $\begin{array}{c}\% \\
\text { (CS) }\end{array}$ & $\begin{array}{c}\% \\
\text { (Deliveries) }\end{array}$ & No. & $\begin{array}{c}\% \\
\text { (CS) }\end{array}$ & (Deliveries) & \\
\hline Left side & 3741 & 57.4 & 16.5 & 8865 & 55.1 & 39.2 & 12606 \\
\hline Right side & 2781 & 42.6 & 12.3 & 7237 & 44.9 & 32.0 & 10018 \\
\hline Total & 6522 & 100.0 & 28.8 & 16102 & 100.0 & 71.2 & 22624 \\
\hline
\end{tabular}

${ }^{*} \mathrm{VD}$ mean vaginal delivery

CS was done for elective causes in $(57.5 \%)$ while emergency CS constituted (42.5\%) with significant statistical difference $(\mathrm{P}=0.000)$ as appeared in table 5:

Table 5: Distribution of the study population according to the types of CS

\begin{tabular}{|l|c|c|c|}
\multicolumn{1}{|c|}{ Type of CS } & No. & $\%$ & \multirow{2}{*}{ P-value $^{*}$} \\
\hline Elective & 386 & 57.5 & \multirow{2}{*}{0.000} \\
\cline { 1 - 3 } Emergency & 285 & 42.5 & \\
\hline \multicolumn{1}{|c|}{ Total } & 671 & 100.0 & - \\
\hline
\end{tabular}

* Chi-square test (Goodness of Fit) was used.

Most of women prefer one method of deliveries (81.8\%) with a significant statistical differences $(P=0.000)$ there was equal prefer for CS and for vaginal delivery among women in this study (50.3\%) and (49.7\%) respectively with non-significant statistical difference $(P=0.898)$ as appeared in table 6 :

Table 6: Mother preference to delivery types among study population

\begin{tabular}{|l|c|c|c|}
\hline \multicolumn{1}{|c|}{ Mother preference $(\mathbf{n = 6 7 1 )}$} & No. of CS & $\%$ & P-value \\
\hline Not prefer any mode of delivery (according to need) & 122 & 18.2 & \multirow{2}{*}{0.000} \\
\cline { 1 - 3 } $\begin{array}{l}\text { Prefer one mode of delivery ( } \mathbf{n = 5 4 9 )} \\
\text { Prefer CS }\end{array}$ Prefer vaginal delivery & 549 & 81.8 & \\
\cline { 2 - 4 } & 276 & 50.3 & \multirow{2}{*}{0.898} \\
\hline Total & 273 & 49.7 & \multirow{2}{*}{-} \\
\hline
\end{tabular}

${ }^{*}$ Chi-square test (Goodness of Fit) was used. 


\section{DISCUSSION}

Caesarean section is the most common surgical procedure in obstetrics and it has been improved, simplified over time and it has become more safe. ${ }^{20}$ The statement "Our journey to the Moon or Mars may be safe but a fetus journey, a journey of only 6 inches through the maternal pelvis is not always safe, for both mother or baby." Said by Patel in 2000. ${ }^{21}$

The finding of this study showed that most age group of women delivered by CS was (20-35) years because in our locality the women with the age of $(\geq 35)$ preferred home deliveries especially if they had previous history of safe home deliveries while women with age group of $(<20)$ years had less married and less fertility rate it was similar to a study in India ${ }^{22}$ which showed that the CS rate was also more in age group of (20-35) years as it constituted $(55.6 \%)$. In the current study three quarters of the women delivered by CS had education of primary school level or illiterate and this high percentage could be explained by the fact that low educational level give less importance to ANC which make complications at time of deliveries more as ANC contributed to a better birth outcome. ${ }^{23}$ This study was similar to study in Kirkuk governorate ${ }^{24}$ where $(70 \%)$ of study sample were primary school level or illiterate. Unemployed women $(91.8 \%)$ was constituted the highest percentage among women delivered by CS and this could be related to low income which make women unable to have ANC. The high number of unemployed women in this study was higher than the rate of unemployed women $(82 \%)$ in Kirkuk governorate. ${ }^{24}$

The prevalence of CS in Mosul city during the study period including home and hospital deliveries was $(18.2 \%)$ which was slightly higher than WHO recommended rate (15\%) and also this rate slightly higher than the rate of CS at 2019 statistic in Mosul city ${ }^{8}$ which was reported as $(15.9 \%)$. In the current study the CS rate in Mosul city between the rate reported among some neighboring governorates linked with the findings of the Iraq annual statistical report at $2018^{5}$ have shown the lowest CS reported in governorate of Al-Anbar (14.2\%) and the highest rate in governorate of Erbil $(52.9 \%)$. The prevalence of CS in Mosul city was much less in comparison to study done by Alsheeha MA in Qassim Saudi Arabia ${ }^{25}$ which constituted (55.4\%).

Considering deliveries in hospitals during the study period and calculating rate of CS of all hospitals in Mosul city was (28.8\%) and clearly explained by the fact of high risk pregnancy and previous two and more CS delivered at hospitals. This rate was slightly higher than that of 2019 statistics and lower than CS rate in five hospitals in Babel, Iraq ${ }^{26}$ were the reported rate was (34.5\%).
Analyzing CS rate in each hospital in Mosul during study period showed that the highest rate was in private hospitals as two of them admitted pregnant women for CS only and one of them admitted limited number of women for vaginal delivery and majority for CS while Nablus Hospital had the lowest percentage in this study with upper limit of WHO recommendation and in the statistic $2019^{8}$ also Nablus Hospital had the lowest percentage with upper limit of WHO recommendation, in the remaining hospitals the percentage were varied between the private and Nablus hospital (had the lowest CS rate among all hospitals) and although there were high number of CS done in these hospital, the percentage is lower than the private because of high number of admission for deliveries (vaginal delivery and CS).

Comparing CS rate between two sides in Mosul city, it was showed that the left side $(57.4 \%)$ was slightly more than the rate in right side although numbers of hospitals from left side was equal to the right side (4 hospitals) this could be explained by presence of two private hospitals in the left side in which the admission was only for CS while the private hospital in the right side had admission for CS in addition to vaginal delivery. There was no similar study including two sides to compare the result with it.

In Mosul city women preferred deliveries at governmental hospitals (93.2\%) and about three quarters of CS (76.7\%) was reported in these hospitals. This could be related to the high numbers of total deliveries in governmental hospitals because trial of labor after caesarean was done only in governmental hospitals and all services in these hospitals were semi cost free for both mother and newborn. Also there was one private hospital in Mosul city which allowed admission for vaginal delivery, it was higher than CS reported in governmental hospitals in Baghdad city ${ }^{27}$ Iraq at it constituted (41.8\%).

In this study elective CS constitutes the higher rate $(57.5 \%)$ among caesarean deliveries and maternal request was also increased the elective CS and it is lower than the study which was done in a tertiary care hospital at Kolkata ${ }^{28}$ in which elective CS was $(81.1 \%)$.

Most of women $(81.8 \%)$ has idea for one mode of deliveries before labor. In this study and about equal numbers of women preferred $C S$ and vaginal delivery. A Study done by Takegata et al, ${ }^{29}$ in Vietnam where pregnant women have preference for CS (34\%). This may be explained by the situation of hospitals in our locality and women preference for CS either in private or even in governmental hospitals and prefer to stay in the hospitals for short period as possible because the hospitals are very crowded in addition to that 
women fear from COVID-19 infection in the study period.

Strength of the current study are the response rate of participant women was (100\%), the reliability index was (96\%), the validity of the questionnaire formula used in the current study was $(86.29 \%)$ and although the sample size required in the study (592) but the researcher increase the sample to (671) while the limitation of current study was some restriction of data collections had occurred during COVID-19.

\section{CONCLUSIONS AND RECOMMENDATIONS}

Caesarean section rate in Mosul city hospitals at a study period was higher than WHO recommendation $(28.8 \%)$. Three quarters of CS was done in governmental hospitals and about half of cases in the left side, $(70.6 \%)$ of women delivered by CS were aged (20-35) years, $(48.4 \%)$ of women with primary school education, (91.8\%) of women were unemployed. The important recommendations in present study which must be given a great attention are the rate of CS should be kept within the optimal range by doing medical check of labor management both in governmental and private hospitals, there is demand for improving and providing cardiotocography (CTG) and fetal blood sampling in all maternal hospitals to check the fetal wellbeing.

\section{ACKNOWLEDGMENTS}

I would like to express my acknowledgments to staff members of Family and Community Medicine Department, College of Medicine, University of Mosul, Iraq.

\section{Conflict of Interest: None.}

\section{REFERENCES}

1. Solanki GC, Cornell J E, Daviaud E ,Fawcus S. Caesarean section rates in South Africa: A case study of the health systems challenges for the proposed National Health Insurance. SAMJ: South African Medical Journal. 2020; 110 (8): 747-750.

2. Osegi N, Makinde Ol. Towards optimizing caesarean section: a five-year review of caesarean sections at a Southern Nigeria hospital. International Journal of Reproduction Contraception, Obstet. Gynecol. 2020; 9 (1): 205-211.

3. Mohammad EM, AL-Ghabban SI, AL-Alak MM. Indications of primary caesarean sections among Iraqi women in Karbala city. International Journal of Current Pharmaceutical Research. 2018; 11
(6): 123-125 . Doi: 10.22159 /ijcpr . 2019 v11i6.36360.

4. Shabila NP. Rates and trends in cesarean sections between 2008 and 2012 in Iraq. BMC pregnancy and childbirth. 2017; 17 (1): 22. https://doi.org/10.1186/s12884-016-1211-6.

5. Ministry of Health / Environment, annual statistical report, Iraq; 2018, Page:38-40.

6. Ministry of Health / Environment, annual statistical report, Iraq; 2019.

7.Nineveh Health Directorate, statistical department, record of births and deaths, 2018.

8.Nineveh Health Directorate, statistical department, record of births and deaths, 2019.

9. Saraya YS, Alashkar AH, Ali MA, Rajab AM, Saquib N. Indications and rate of first cesarian delivery in central region's maternity and children hospital. Saudi Medical Journal. 2019; 40 (12): 1251-1255. Doi:10.15537/smj.2019.12.24736.

10. Batieha AM, Al-Daradkah SA, Khader YS, Basha A, Sabet F, Athamneh TZ and et al. Cesarean Section: Incidence, Causes, Associated Factors and Outcomes: A National Prospective Study from Jordan. Gynecol. Obstet. Case Rep. 2017; 3 (3): 55.

11. Al-Hammami $\mathrm{H}$ and Alsharif $\mathrm{M} \mathrm{N}$. Prevalence of Cesarean Section at AL-Tawlid Hospital during the Syrian Crisis. Journal of medical pharmaceutical and allied sciences. 2017; 6 (2): 947-953. Doi:10.22270/jmpas.v6i12.746.

12. Erbaydar NP, Erbaydar T. Relationship between caesarean section and breastfeeding: evidence from the 2013 Turkey demographic and health survey. BMC Pregnancy and Childbirth. 2020; 20 (1): 55.

13. Matin BK, Hajizadeh M, Najafi F, Rad E H, Piroozi B, Rezaei S. The impact of health sector evolution plan on hospitalization and cesarean section rates in Iran: an interrupted time series analysis. International Journal for Quality in Health Care. 2018 February ; 30 (1): 75-79.

14. Betrán AP, Torloni MR, Zhang J, Gülmezoglu AM. WHO Working Group on Caesarean Section. WHO statement on caesarean section rates. BJOG. 2016; 123 (5): 667-70. Doi: 10.1111/1471-0528.13526.

15. BegumT, Rahman A, Nababan $H$, Hoque DM.E, Khan AF, Ali T and et al. Indications and determinants of caesarean section delivery: Evidence from a population-based study in Matlab, Bangladesh. PLoS ONE. 2017; 12 (11): e0188074.

16. Boerma T, Ronsmans C, Melesse DY, Barros AJ, Barros FC, Juan $L$ and et al. Global epidemiology of use of and disparities in caesarean sections. The Lancet. 2018; 392 (10155): 1341-1348. 
17. Montilla P, Merzagora F, Scolaro E, Requejo J, Ricciardi W, Meli $E$ and et al. Lessons from a multidisciplinary partnership involving women parliamentarians to address the overuse of caesarean section in Italy. BMJ Global Health. 2020; 5 (2): e002025.

18. Uno K, Mayama M, Yoshihara M, Takeda T, Tano S, Suzuki T and et al. Reasons for previous Cesarean deliveries impact a woman's independent decision of delivery mode and the success of trial of labor after Cesarean. BMC Pregnancy and Childbirth. 2020; 20 (1): 1-8.

19. Byamugisha J , Adroma M. Caesarean Section in Low, Middle and High Income Countries. In Recent Advances in Cesarean Delivery, 2020.

20. Hounkpatin B, Aboubakar M, Dangbemey P, Tognifode V, Schantz C, Dumont A and RenéPerrin R X. Practice of the Caesarean Section in Four Maternities in Benin Using Robson Classification. Open Journal of Obstetrics and Gynecology. 2020; $10 \quad$ (1): 65-75. https://doi.org/10.4236/ojog.2020.101006.

21. Patel BS, Patel AB, Patel AJ, Banker DA ,Patel MB. Maternal and Neonatal Outcome in Elective Versus Emergency Cesarean Section in A Tertiary Healthcare Centre in Ahmedabad, Western India. British Journal of Medical \& Health Sciences (BJMHS). 2020; 2 (5): 231-240.

22. Verma V, Vishwakarma RK, Nath DC, Khan HTA, Prakash R, Abid O. Prevalence and determinants of caesarean section in South and South-East Asian women. PLoS ONE. 2020; 15 (3): e0229906.

23. Okeke EN, Wagner Z Abubakar IS. Maternal Cash Transfers Led To Increases In Facility Deliveries And Improved Quality Of Delivery Care In Nigeria: Study examines the prevalence of delayed entry, the reasons for the delays and their effect on Medicaid spending in a recent cohort of brand-name medications. Health Affairs. 2020; 39 (6): 1051-1059.

24. Salih HS. Mothers Fear from Caesarean Section in Kirkuk City. kufa Journal for Nursing Sciences. 2016; 6 (1): 224-229. ISSN: 22234055.

25. Al-Sheeha M. Epidemiology of Cesarean Delivery in Qassim, Saudi Arabia. Journal of Medical Science, 2018 May 20; 6(5): 891-895.

26. Hassain GS. Cesarean section in Babylon Province. Int. Journal Medicine Sci. 2015; 3 (4): 113-115.

27. Al-Naimy MM, Yassin BG, AL-Kazzaz HB. Comparison of Rate of Caesarean Section between Governmental and Private Hospitals in Baghdad City. The Iragi Post graduate Medical Journal. 2013; 12 (2): 288-295.

28. Chakrabarti S. Frequency and Indication of Emergency Caesarean Section in a Tertiary
Care Hospital in Kolkata: Analysis of Secondary Data. Natl. Journal Community Medicine. 2018; 9 (1): 5-9.

29. Takegata M, Smith $\mathrm{C}$, Nguyen $\mathrm{H} \mathrm{A}$, Thi $\mathrm{H} \mathrm{H}$, Thi Minh T N, Day L T et al. Reasons for Increased Caesarean Section Rate in Vietnam: A Qualitative Study among Vietnamese Mothers and Health Care Professionals. In Healthcare. Multidisciplinary Digital Publishing Institute. 2020; 8 (1): 41. 